\title{
Análise do Ambiente de Marketing: Um estudo aplicado em uma Cooperativa do Setor de Agronegócios da Região Centro-Oeste do Rio Grande do Sul
}

\author{
Analysis of Marketing Environment: A study applied in a cooperative agribusiness \\ sector of the Central-West Region of Rio Grande do Sul
}

\begin{abstract}
Resumo
Conhecer o ambiente no qual está inserida constitui-se, no mercado atual, em uma das mais importantes estratégias que podem ser adotadas pelas organizações. No caso das cooperativas, o teor de importância de aplicação é o mesmo. Sendo assim, o objetivo geral deste estudo foi realizar uma análise ambiental, a nível micro e macroambiente, em uma cooperativa de agricultores parceiros da região centro-oeste do estado do Rio Grande do Sul. A viabilização da pesquisa se deu por meio de um estudo de caso acrescido de uma pesquisa de campo onde os pesquisadores atuaram diretamente na observação dos fenômenos. A partir do desenvolvimento da análise do ambiente de marketing da cooperativa pode-se inferir que a cooperativa possui uma enorme gama de fatores influenciadores e que, com a análise, uma visão sistêmica poderá ser aplicada em prol do estabelecimento de ações que busquem o aumento da lucratividade e a consolidação da cooperativa no mercado.
\end{abstract}

Palavras chave: Cooperativa, marketing, análise ambiental, agronegócios.

\begin{abstract}
Get to know the environment in which it operates is, in today's market, in one of the most important strategies that can be adopted by organizations. In the case of cooperatives, the importance of application content is the same. Therefore, the overall objective of this study was to conduct an environmental analysis, the micro level and in a cooperative of macro environmental farmers partners from the central-west of the State of Rio Grande do Sul. The feasibility of the research took place through a case study and a field where researchers acted directly on the observation of phenomena. From the development of the marketing environment analysis of the cooperative can infer that the cooperative has a huge range of factors influencing and that, with the analysis, a systemic view can be applied for the establishment of actions that seek to increase the profitability and the consolidation of the cooperative in the market.
\end{abstract}

Keywords: Cooperative, marketing, environmental analysis, agribusiness.

Recebido: 10/11/2015 Aceito: 29/02/2016

\footnotetext{
Flavia Luciane Scherer ${ }^{1}$, Maíra Nunes Piveta ${ }^{2}$, Roberto Vasconcelos Boemo ${ }^{3}$, Fabricio Nunes Gomes ${ }^{4}$ e Marindia Brachak dos Santos 5

${ }^{1}$ Universidade Federal de Santa Maria, Doutora em Administração- flaviascherer@globo.com- Universidade Federal de Santa Maria, Centro de Ciências Sociais e Humanas, Departamento de Ciências Administrativas. Av. Roraima, 1000 prédio 74 C, Camobi ,Santa Maria, RS, CEP 97105-900

2 Universidade Federal de Santa Maria, Bacharel em Administração- mairapivetasm@ hotmail.com

${ }^{3}$ Centro Universitário Franciscano, Bacharel em Administração-roberto_boemo@ hotmail.com

${ }^{4}$ Universidade do Sul de Santa Catarina, Graduando em Administração - fabricionunesgomes@gmail.com

${ }^{5}$ Universidade Federal de Santa Maria, Doutoranda em Administração - marindiabrachak@gmail.com
} 


\section{Introdução}

$\mathrm{N}$ o cenário mercadológico atual, onde a globalização já se tornou um assunto superado, em termos de novidade, devido à sua crescente aplicabilidade em todo e qualquer tipo de negócio, os gestores precisam necessariamente estar atentos tanto ao ambiente interno quanto ao externo em que suas empresas estão inseridas. Isto ocorre, pois, a identificação das necessidades e tendências ainda não atendidas precisa ser uma constante no desenvolvimento de ações que culminem na lucratividade empresarial.

Empresas que se preocupam em conhecer o seu mercado de atuação e todas as forças que possam vir a interferir em seus planos estão mais propensas a alcançar níveis de sucesso e bom desempenho comprovadamente superior àquelas que sequer se interessam em conhecer o seu público consumidor. Ignorar a análise ambiental do negócio é quase como navegar perdido em um oceano, não se sabe aonde irá se chegar e muito menos quais serão os imprevistos a serem enfrentados.

Atentas à competitividade cada vez mais voraz do mercado, cresce significativamente o número de gestores que buscam interpretar as variáveis impactantes de suas organizações buscando por meio da análise ambiental de marketing conhecer em qual oceano se está navegando. Desta forma, o objetivo geral deste estudo é realizar uma análise ambiental, a nível micro e macroambiente, em uma cooperativa de agricultores parceiros da região centro-oeste do estado do Rio Grande do Sul.

O estudo justifica-se mediante a importância que a análise ambiental possui, em todo e qualquer tipo de negócio, que busca manter-se competitivo no mercado onde atua. Corroborando, Ribeiro e Picinin (2012) argumentam que o microambiente e o macroambiente de marketing são responsáveis por ditar as tendências do mercado. No caso da cooperativa analisada, que busca constantemente desenvolver-se e crescer de forma sustentável constitui-se em uma importante ferramenta norteadora para a tomada de decisões, planejamento de ações e visão sistêmica de mercado.

Dado o exposto, o trabalho encontra-se estruturado em cinco capítulos. O primeiro refere-se à introdução dando sequência ao segundo capítulo que embasa teoricamente o trabalho. Posteriormente a metodologia é apresentada e no quarto capítulo os resultados são expostos. Por fim têm-se a conclusão no quinto capítulo e as referências utilizadas no estudo.

Cabe salientar ainda, que objetivando preservar a identidade da Cooperativa optou-se por remeter-se à ela, neste estudo, pelo nome fictício de Omega.

\section{Referencial Teórico}

\subsection{Ambiente de Marketing}

O ambiente de marketing consiste em fatores e forças externas que influenciam positiva ou negativamente a administração de marketing em seu relacionamento com os clientes-alvo. As empresas bem-sucedidas sabem a importância da constante observação e adaptação às mudanças do ambiente, pois ele pode oferecer tanto as oportunidades quanto as ameaças (KOTLER; ARMSTRONG, 2000). De acordo com Kotler e Armstrong (2000), em decorrência disto é que a responsabilidade pela identificação dos fatores que possam modificar o ambiente é dos profissionais de marketing.

Na percepção de Kotler e Keller (2006), o ambiente de marketing divide-se em Macro e Microambiente. Nas próximas subseções, as definições específicas a respeito das segmentações do ambiente de marketing serão apresentadas.

\subsubsection{Macroambiente}

O macroambiente pode ser entendido, de acordo com Palmer (2006), pelas forças tecnológicas e econômicas, político-legais e socioculturais existentes, são as forças que estão afastadas da organização, mas que mesmo assim impactam diretamente no desempenho das mesmas. Outros autores acrescentam algumas outras variáveis para o macroambiente, como Kotler e Keller (2006), que acrescentam as forças demográficas e naturais, e ainda Minadeo (2008), que acrescenta a ecologia, o comportamento do consumidor e forças da natureza.

Diante disto, torna-se imprescindível fazer uma previsão do futuro para antecipar problemas e ultrapassar a mera perspectiva de sobrevivência para as empresas. Hoje, vencem os que visualizam cenários, os que não querem ser surpreendidos pelas surpresas desagradáveis do amanhã (BOONE; KURTZ, 1998). Dado o exposto, a seguir será apresen- 
tada uma síntese dos principais elementos inerentes à análise macroambiental de uma organização.

- Ambiente Econômico: Os fatores econômicos referem-se ao estágio da economia (em depressão, recessão, recuperação ou prosperidade), às tendências nos preços de bens e serviços (inflação ou deflação), às políticas monetárias e fiscais, ao balanço de pagamentos etc. Cada uma dessas facetas da economia pode facilitar ou dificultar o alcance dos objetivos da empresa e o sucesso ou fracasso de sua estratégia (CHIAVENATO, 2007).

- Ambiente Político Legal: Os fatores políticos dizem respeito a decisões governamentais no nível federal, estadual e municipal capazes de afetar as atividades e operações da empresa. A legislação nos âmbitos federal, estadual e municipal vem afetando cada vez mais as operações e atividades das empresas. A legislação sobre assuntos, como salários e controles de preços, higiene e segurança do trabalho, concessão de crédito direto ao consumidor, construção de edifícios, condições de trabalho, faturamento, estocagem e depósitos de matérias-primas e de produtos acabados, além de impostos e uma infinidade de outros aspectos, tornam a atividade empresarial sujeita a limitações e restrições legais. Muitas vezes, a estratégia empresarial esbarra em certos impedimentos legais (CHIAVENATO, 2007).

- Ambiente Sociocultural: Uma sociedade politicamente organizada deve exigir de empresas, igrejas, escolas, governos e demais organizações o desenvolvimento de projetos sociais. Para tanto, é imprescindível a apresentação de um balanço social, conjunto de informações sobre o desempenho de uma instituição em benefício da comunidade (PAULA, 2012).
- Ambiente Tecnológico: A tecnologia é, simultaneamente, uma força externa e ambiental que impõe desafios e problemas à empresa, e uma força interna que também lhe impõe desafios e problemas, mas permite maior eficiência na utilização dos seus recursos disponíveis para o efetivo alcance de seus objetivos quando dominada. Todavia, uma coisa é certa: todas as empresas dependem de algum tipo de tecnologia ou conjunto de tecnologias para funcionar e alcançar seus objetivos (CHIAVENATO, 2007).

- Ambiente Natural: A economia do meio ambiente concentra-se excessivamente na análise dos custos da despoluição e na alocação destes, de acordo com o princípio do poluidor pagador. Na medida em que a responsabilidade ambiental se traduz por um custo adicional, o custo da poluição passa a estar internalizado no custo do produto final, a competitividade da empresa é afetada. Em decorrência, no plano macroeconômico há uma arbitragem entre um maior crescimento selvagem ou um menor crescimento em harmonia com a natureza (ALMEIDA; MELLO; CAVALCANTI, 2001).

\subsubsection{Microambiente}

De acordo com Minadeo (2008), o microambiente é aquele mais diretamente próximo à empresa envolvendo fatores como os fornecedores, distribuidores, concorrentes, consumidores e legislação. No Quadro 1 a seguir, será apresentada uma síntese das definições teóricas a respeito dos elementos da análise microambiental. 
Quadro 1 - Síntese teórica dos elementos do microambiente

\begin{tabular}{|c|c|}
\hline Componentes & Contribuição Teórica \\
\hline Fornecedores & $\begin{array}{l}\text { A escolha dos fornecedores tem grande importância no planejamento da } \\
\text { empresa. É preciso descobrir quem são, onde se localizam os fornecedores e } \\
\text { quais são os mais adequados para o seu negócio. Por outro lado, obter boas } \\
\text { condições de compras depende de negociação permanentemente com os } \\
\text { fornecedores e ter atenção às oportunidades. Quanto mais tempo se ganhar } \\
\text { para pagar o fornecedor, melhor para seu caixa (SEBRAE, 2012). }\end{array}$ \\
\hline Clientes & $\begin{array}{l}\text { Por definição, considera-se como cliente de uma entidade todo aquele que } \\
\text { decide a compra de determinado bem ou serviço oferecido por essa mesma } \\
\text { entidade. Assim, pode-se distinguir o cliente direto (aquele que compra } \\
\text { diretamente à entidade e que poderá ser um intermediário ou distribuidor) e } \\
\text { o cliente final (aquele que compra para satisfação de uma necessidade sua ou } \\
\text { de alguém a quem oferece o bem) (NUNES, 2009). }\end{array}$ \\
\hline Concorrentes & $\begin{array}{l}\text { Podem disputar clientes, consumidores ou usuários, como é o caso de em- } \\
\text { presas que oferecem os mesmos produtos ou serviços colocados no mesmo } \\
\text { mercado consumidor. Podem disputar também os recursos necessários, como } \\
\text { é o caso de empresas que precisam das mesmas entradas, entre as quais } \\
\text { dinheiro, materiais e matérias-primas, máquinas e equipamentos, tecnologia, } \\
\text { recursos humanos, serviços. A concorrência quanto a saídas ou entrada pro- } \\
\text { voca alterações no mecanismo de ofertas e procura do mercado, interferindo } \\
\text { nas disponibilidades, nos preços, na qualidade e na relativa facilidade ou } \\
\text { dificuldade na obtenção dos recursos indispensáveis às operações da empre- } \\
\text { sa. A concorrência afeta a dinâmica do ambiente, provocando turbulência e } \\
\text { reatividade ambiental (CHIAVENATO, 2007). }\end{array}$ \\
\hline $\begin{array}{c}\text { Órgãos Regula- } \\
\text { dores }\end{array}$ & $\begin{array}{l}\text { Como, por exemplo, entidades governamentais, sindicatos, associações de } \\
\text { classe, opinião pública, que interferem nas atividades e operações da empre- } \\
\text { sa, quase sempre para vigiá-las e provocar restrições e limitações, reduzindo } \\
\text { o grau de liberdade no processo de tomada de decisão da empresa. Em casos } \\
\text { de hostilidade neste setor do ambiente de tarefa, a empresa precisa adotar } \\
\text { estratégias bem planejadas e implementadas para reduzir ou neutralizar as } \\
\text { coações e ameaças externas (CHIAVENATO, 2007). }\end{array}$ \\
\hline
\end{tabular}

Fonte: Elaborado pelos autores com base nas referências bibliográfica

De acordo com Ribeiro e Picinin (2012), os fatores microambientais são intensamente conectados entre si sendo, os clientes, o elemento central.

A partir do exposto tornou-se possível familiarizar-se com os principais fatores microambientais existentes no meio organizacional. Os mesmos são responsáveis por exercer influência direta no cotidiano e bom funcionamento empresarial. A análise periódica destes elementos se constitui indispensável vista de forma estratégica.

\section{Procedimentos Metodológicos}

Quanto ao objetivo, a pesquisa classifica-se como descritiva e exploratória devido ao fato de haver levantamento bibliográfico e entrevistas com pessoas que possuam experiência prática com o problema pesquisado e possam agregar informações mais pontuais e específicas.

A pesquisa exploratória foca na maior familiaridade com o problema, com vistas a torná-lo mais explícito ou a facilitar a construção de hipóteses. Este tipo de pesquisa tem como principal objetivo o aprimoramento de ideias ou a descoberta de intuições ou até mesmo novas ideias.

Este tipo de pesquisa (exploratória) é extremamente flexível, de modo que quaisquer aspectos relativos ao fato estudado têm importância. Grande parte das pesquisas do tipo envolve levantamento bibliográfico, documental e entrevista ou questioná- 
rio envolvendo pessoas que tiveram alguma experiência com o problema (GIL, 1991).

A viabilização da pesquisa se dará por meio de um estudo de caso acrescido de uma pesquisa de campo onde os pesquisadores atuaram diretamente na observação dos fenômenos referentes ao objetivo deste estudo. Na Figura 1 a seguir, buscando transmitir um maior entendimento a respeito da metodologia do trabalho, foi desenvolvido um desenho de pesquisa.

Figura 1 - Desenho de pesquisa

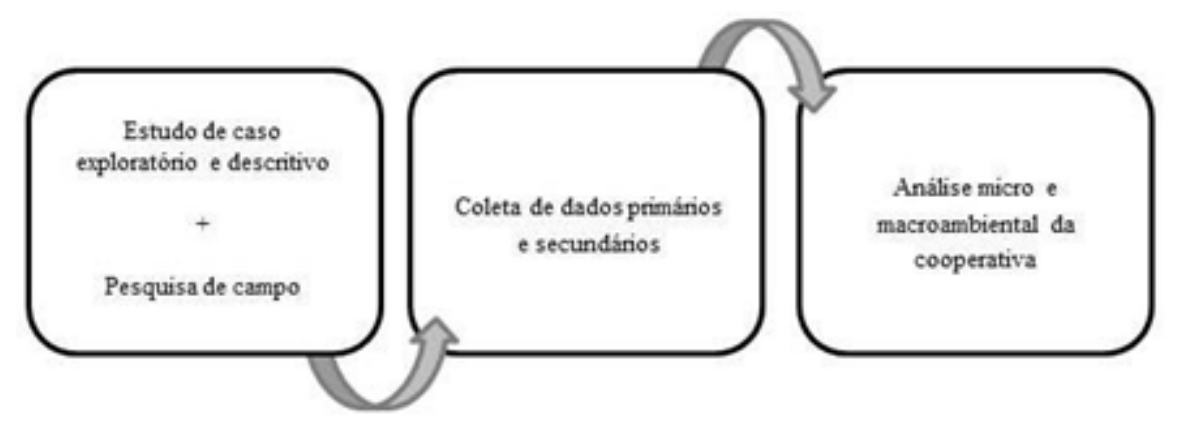

Fonte: Elaborado pelos autores

De acordo com a Figura 1, tornou-se possível visualizar a forma com que se buscou viabilizar este estudo segmentando-o em três momentos representativos distintos.

\section{Análise dos Resultados}

Neste capítulo, os resultados obtidos mediante a execução da pesquisa serão apresentados. Primeiramente a cooperativa e os seus valores serão expostos passando-se, posteriormente, para a análise do ambiente de marketing da cooperativa.

\subsection{A Cooperativa}

A Cooperativa Omega foi fundada no ano de 2000 por um grupo de agricultores com o objetivo de fornecer aos associados condições para melhor desenvolver suas atividades agrícolas e atualmente possui cerca de 1800 cooperados.

A Cooperativa Omega está sediada em Santa Maria, na BR-392, possuindo 3 filiais localizadas nas cidades de Cachoeira do Sul, São Gabriel e Rosário do Sul. A Cooperativa conta com cerca de 70 colaboradores distribuídos entre matriz e filiais ocupando os seguintes cargos: vendedores, motoristas, auxiliares do departamento de estoque e administrativo. A Omega tem o foco principal, atualmente, nas culturas do arroz e soja e leva até o agricultor assistência desde o plantio; fornecendo fertilizantes, escolha de cultivares, tratando sementes e controlando pragas; até o recebimento e comercialização dos grãos.

A missão da Omega é: estabelecer e manter relacionamentos de parcerias com os funcionários, cooperados e fornecedores por meio de fidelidade $\mathrm{e}$ confiança, fazendo com que os envolvidos no processo tenham ganhos econômicos e pessoais.

Desta maneira, a Cooperativa, os fornecedores e os clientes terão benefícios reais com a consolidação dos negócios realizados em comum. Seus valores compreendem respeito ao ser humano e a pátria; preservação do meio ambiente; divulgação e aplicação de tecnologias comprovadamente eficientes; crescimento profissional e pessoal da equipe de colaboradores e clientes e contribuição para o crescimento econômico regional.

\subsection{Análise Ambiental}

Nesta seção, será exposta a análise do ambiente de marketing realizada na cooperativa Omega.

\subsubsection{Análise do Macroambiente}

A análise externa é composta de fatores, ou cenários, oriundos do macroambiente organizacional e compreendem, por sua vez, análises de informações econômicas, tecnológicas, políticas, legais, sociais e 
também culturais. Basicamente, é realizada uma análise das variáveis com potencial externo de interferência no negócio. Desta forma, o cenário é a descrição, qualitativa e/ou quantitativa, de situações futuras e hipotéticas, a respeito de uma empresa, região, país ou bloco, dentro de um determinado horizonte de tempo (CHIAVENATO, 2004).

Dado o exposto, nas próximas subseções será apresentada a análise do macroambiente da Cooperativa de acordo com o estudo realizado.

\subsubsection{Ambiente Econômico}

No que tange a análise do ambiente econômico da cooperativa em questão, observou-se que o fator que mais apresenta influência é a variação da taxa de câmbio do dólar e as políticas agrícolas e de exportação. Outra ocorrência do ambiente econômico que impacta diretamente na Omega são as crises de ordem mundial. Isto se deve ao fato de o setor de atuação da cooperativa, neste caso o primário, pautar-se quase que exclusivamente em eventos e fatores de cunho internacional. Isto culmina em uma grande influência nos resultados da Omega e dos agricultores parceiros também.

A economia mundial apresenta significativo reflexo nas ações da Cooperativa devido ao trabalho direto com o mercado externo. A movimentação do mercado mundial é constantemente acompanhada e notícias do mercado agrícola internacional são fatores de grande impacto na formação de preços para a cooperativa. A situação pode ser exemplificada mediante o noticiamento de um período de estiagem nos Estados Unidos da América onde as cotações da soja e do dólar seriam imediatamente alteradas.

Além disso, outro país que possui grande influência na agricultura brasileira, em especial da soja e consequentemente na cooperativa, é a China que se apresenta como a principal compradora de soja do mundo, além de ser uma das principais economias mundiais. O próximo tópico será destinado a tratar do ambiente político legal inerente à cooperativa estudada.

\subsubsection{Ambiente Político Legal}

Analisando-se o Ambiente Político Legal da Cooperativa Omega observou-se que qualquer tipo de estratégia política adotada pelo governo, em especi- al, modificações nas taxas de importação; incentivo à exportação; alterações na legislação trabalhista e principalmente a situação econômica do país, afetam diretamente nos preços praticados na cooperativa interferindo no poder aquisitivo dos clientes parceiros da Omega.

Levando-se em consideração que a cooperativa, assim como qualquer outra empresa, possui funcionários e que a mesma ainda realiza a comercialização de produtos agrotóxicos, as leis ambientais e trabalhistas aplicam-se diretamente na mesma influenciando o desempenho final e exigindo a adoção de uma série de medidas diferenciadas de gestão de riscos ambientais.

As legislações brasileiras vigentes mostram-se extremamente rígidas com as organizações que comercializam produtos que apresentam potencial de riscos ambientais. Como a Cooperativa se enquadra nestas especificações, esta tende constantemente a regularizar-se de acordo com as imposições legais cobradas perante as nocividades que produtos deste tipo podem apresentar para o meio ambiente e a sociedade.

A logística reversa das embalagens de agrotóxicos, por exemplo, é uma das ações que a cooperativa pratica vislumbrando adequar-se às exigências legislativas impostas.

Desta forma, diante da complexidade da regulamentação imposta, podendo inclusive acarretar em multas muito onerosas mediante o descumprimento legal ou em caso de possíveis vazamentos de produtos tóxicos. Sendo assim, a Cooperativa apresenta-se bastante impactada pelo ambiente político legal onde se encontra.

\subsubsection{Ambiente Sociocultural}

Conduzindo-se a análise do ambiente sociocultural da Omega observou-se que a Cooperativa preocupa-se em contribuir de alguma forma com a sociedade na qual está inserida. Sendo assim, foi criado o Programa de Apoio Comunitário baseado no conceito de cidadania empresarial, sob o qual a cooperativa se compromete com as questões que envolvem a comunidade onde se encontra. No Quadro 2 a seguir, as ações desenvolvidas pela Cooperativa mediante o comprometimento realizado estão expostas. 
Quadro 2 - Ações desenvolvidas pela cooperativa

\begin{tabular}{|c|}
\hline Ações de cunho social, cultural e ambiental realizadas pela Omega \\
\hline Auxílio às instituições filantrópicas que são apoiadas por meio de patrocínio de eventos desenvolvidos por estas entidades. \\
\hline $\begin{array}{c}\text { Realiza o apoio direto ou a intermediação junto a seus fornecedores, do levantamento de verbas para atividades de } \\
\text { divulgação de trabalhos ou atividades técnicas promovidas pelo Centro de Ciências Rurais da UFSM, Sociedade de } \\
\text { Agronomia de Santa Maria, Secretarias de Agricultura dos Municípios de sua área de atuação, bem como atividades } \\
\text { técnicas desenvolvidas pelo Centro Federal de Educação Tecnológica de São Vicente do Sul. }\end{array}$ \\
$\begin{array}{c}\text { Detecta e encaminha à direção da Cooperativa, programas que visam beneficiar a comunidade onde está inserida, contando } \\
\text { com parceiros fornecedores como, por exemplo, fornecendo brindes para sorteios em eventos que visam angariar recursos } \\
\text { para melhoramentos destas comunidades. }\end{array}$ \\
\hline $\begin{array}{c}\text { Realiza palestras sobre uso adequado de agrotóxicos, descarte de embalagens vazias dentre outros assuntos que } \\
\text { dizem respeito à proteção ambiental nas comunidades rurais, escolas, universidades, associações de classe e empresas, por } \\
\text { meio de suas equipes técnicas. }\end{array}$ \\
\hline
\end{tabular}

Fonte: Elaborado pelos autores

Por meio da interpretação do que foi exposto no quadro anterior evidencia-se uma preocupação da Cooperativa em se manter atuante e criando impactos positivos na sociedade e nos grupos onde apresenta uma participação mais relevante como, por exemplo, oportunizar aprendizado aos alunos matriculados nos cursos relacionados às áreas de atuação da Cooperativa, oferecidos nas instituições de ensino locais.

Cabe salientar ainda, que a Omega apresenta um comportamento ambientalmente responsável mediante o fomento de ações que minimizem o impacto no meio ambiente que alguns de seus produtos podem vir a causar, caso sejam erroneamente descartados, como é o caso das embalagens vazias de agrotóxicos.

\subsubsection{Ambiente Tecnológico}

No que diz respeito ao ambiente tecnológico, a Cooperativa busca atualizar-se constantemente quanto aos avanços advindos da tecnologia agrícola mundial que impacta diretamente no setor de atuação da mesma. Os técnicos são constantemente capacitados por meio de palestras, visitas à campo proferidas pelos próprios fornecedores, proporcionando atualização tecnológica e melhoria da lucratividade nas propriedades rurais dos agricultores parceiros.

A cooperativa não possui, ainda, tecnologias recentes na parte de softwares para controle de estoque fazendo com que a maioria dos controles seja feito de forma manual. Já no âmbito técnico, a em- presa possui uma tecnologia bem avançada, possuindo, em destaque, um método de classificação e de avaliação de sementes que proporciona um melhor desempenho e produtividade dos cultivares comercializados pela cooperativa.

\subsubsection{Ambiente Natural}

Quanto ao ambiente natural, a Omega preocupase em realizar ações de conscientização por meio de palestras sobre o uso adequado de agrotóxicos bem como o descarte correto das embalagens vazias dentre outros assuntos que dizem respeito à proteção ambiental.

Durante as atividades de assistência técnica nas propriedades rurais, o técnico responsável procura orientar os aplicadores para que realizem as tarefas que envolvam produtos químicos de forma a não se contaminarem e preservarem o meio ambiente. $\mathrm{Ci}$ ta-se como exemplo, a utilização correta de Equipamento de Proteção Individual (EPI), realização da tríplice lavagem, armazenamento correto das embalagens, regulagem de implementos pulverizadores.

\subsubsection{Análise do Microambiente}

A análise microambiental da Cooperativa Omega se dedicará a descrever e analisar os componentes oriundos do ambiente interno da cooperativa e as ações praticadas com relação à estes. Aspectos como fornecedores, clientes, concorrentes e órgãos reguladores serão apresentados. 


\subsubsection{Fornecedores}

Realizando-se uma investigação a respeito dos fornecedores da Cooperativa, descobriu-se que a mesma trabalha com oito empresas que lhes fornecem os seus principais produtos de comercialização, as sementes para cultivares, os fertilizantes e os agrotóxicos utilizados nas propriedades rurais dos clientes da cooperativa.

Dado o exposto, os fornecedores da Omega são: Bayer CropScience, Bunge, Chemtura, FMC, Monsanto,Ihara, Nortox, Buffon S.A. No Quadro 3 a seguir, um breve histórico de cada uma das empresas e o tempo de relacionamento com a Cooperativa será apresentado.

\section{Quadro 3 - Fornecedores da Cooperativa e a sua descrição}

\begin{tabular}{|c|c|}
\hline Fornecedor & Descrição \\
\hline Bayer CropScience & $\begin{array}{l}\text { É uma das líderes mundiais em inovação no segmento de ciências agríco- } \\
\text { las, que por sua vez engloba as áreas de proteção de cultivos, sementes e } \\
\text { biotecnologia vegetal, além de soluções para o segmento de saúde ambien- } \\
\text { tal.Com sede em Monheim, Alemanha, a empresa está presente em mais } \\
\text { de } 120 \text { países, no Brasil, são mais de } 900 \text { colaboradores, numa instalação } \\
\text { industrial em Belford Roxo no Rio de Janeiro e uma Estação Experimental } \\
\text { no Estado de São Paulo. É parceira da Omega desde o ano } 2000 \text {, sendo } \\
\text { uma das principais fornecedoras da empresa, fornecendo uma linha com- } \\
\text { pleta de defensivos agrícolas. As compras feitas pela Omega são sempre } \\
\text { em grandes quantidades e em momentos oportunos, sempre próximos ao } \\
\text { plantio das culturas de soja e arroz. }\end{array}$ \\
\hline Bunge & $\begin{array}{l}\text { A Bunge, presente no Brasil desde 1905, é uma das principais empresas do } \\
\text { agronegócio e alimentos do país, conquistando a liderança em originação } \\
\text { de grãos e processamento de soja e trigo, na produção de fertilizantes, na } \\
\text { fabricação de produtos alimentícios e em serviços portuários. É uma das } \\
\text { maiores exportadoras do Brasil (a primeira em agronegócio), contribuindo } \\
\text { de maneira substancial para o saldo positivo da balança comercial e para } \\
\text { as divisas para a economia nacional. É fornecedora da Cooperativa desde } \\
\text { 2002, fornecendo fertilizantes usados principalmente nas culturas de soja, } \\
\text { arroz e trigo. }\end{array}$ \\
\hline Chemtura & $\begin{array}{l}\text { É uma das maiores companhias de especialidades químicas dos Estados } \\
\text { Unidos e um dos maiores produtores e comercializadores de aditivos plás- } \\
\text { ticos do mundo. Fabrica e comercializa produtos químicos especiais, po- } \\
\text { límeros e produtos químicos para agricultura. Parceira da Cooperativa } \\
\text { Omega desde } 2010 \text { fornece aditivos siliconados usados para diminuir a } \\
\text { deriva nas pulverizações. A participação da Omega ainda é pequena e as } \\
\text { compras ainda são feitas em pequenas quantidades. }\end{array}$ \\
\hline FMC & $\begin{array}{l}\text { A organização está a quase } 130 \text { anos realizando conquistas, gerando em- } \\
\text { pregos e melhorias na área rural e na vida das pessoas. Foi em } 1883 \text { que o } \\
\text { norte-americano e inventor aposentado John Bean criou uma bomba pul- } \\
\text { verizadora para a aplicação de defensivos agrícolas. Sua ideia era comba- } \\
\text { ter com mais eficiência as pragas que infestavam os pomares de amendo- } \\
\text { eiras na Califórnia e comprometiam toda a safra. A invenção foi um su- } \\
\text { cesso, pois, além de atingir seu objetivo, deu início à criação da FMC } \\
\text { Corporation. Sendo um dos principais parceiros da Omega há quase nove } \\
\text { anos, o principal produto da FMC revendido pela cooperativa, é o herbici- } \\
\text { da GAMIT, usado principalmente na cultura de arroz. }\end{array}$ \\
\hline Monsanto & $\begin{array}{l}\text { Chegou oficialmente ao Brasil em } 1963 \text { e sua sede no país localiza-se em } \\
\text { São Paulo, mesmo estado onde foi instalada a primeira fábrica, na cidade } \\
\text { de São José dos Campos, em } 1976 \text {. No Brasil, dedica-se a produzir herbi- } \\
\text { cidas e sementes de milho, soja, algodão e hortaliças, e variedades de } \\
\text { cana-de-açúcar, produtos que ajudam os agricultores a produzir mais, com } \\
\text { menos recursos naturais. Fornecedora principalmente de herbicida, é uma } \\
\text { das principais fornecedoras da Omega desde o ano } 2000 \text {. }\end{array}$ \\
\hline
\end{tabular}




\begin{tabular}{|c|l|}
\hline \multicolumn{1}{|c|}{ Continuação } \\
Ihara S.A. Indústrias Químicas \\
\begin{tabular}{|l} 
Atua desde 1965 no mercado e possui em seu portfólio mais de 60 produ- \\
tos para as mais diversas culturas e também para o controle de pragas \\
domésticas. A IHARA produz fungicidas, herbicidas, inseticidas, nutrien- \\
tes, produtos especiais, domissanitários e fumigantes. Fornece para a Coo- \\
perativa Omega, principalmente fertilizantes, desde 2002 quando ainda era \\
chama-se Trevo, sendo então adquirida pela IHARA.
\end{tabular} \\
\hline Foi fundada em 14 de abril de 1954, em Apucarana no estado do Paraná. \\
Iniciou suas atividades como indústria formuladora de inseticida em pó, \\
destinado a combater a broca do café, numa época em que os cafezais \\
eram uma das maiores fontes de riquezas do Brasil, cobrindo uma área \\
contínua que ia do Norte Pioneiro às barrancas do Rio Paraná. A década \\
de 80 foi marcada por grandes mudanças na agricultura. O plantio direto \\
só se tornou possível quando, em 1983, a Nortox passou a produzir, de \\
forma pioneira no Brasil, o herbicida Glifosato. Com isso, o preço do \\
Glifosato baixou significativamente e o plantio direto pôde ser adotado em \\
todo o Brasil. Fornece uma linha completa de defensivos agrícolas genéri- \\
cos para a Cooperativa Omega, desde 2005, sendo uma das principais \\
fornecedoras da empresa. As compras geralmente são realizadas em gran- \\
des quantidades e, em época de sazonalidade, mensalmente.
\end{tabular}

Fonte: Elaborado pelos autores

De acordo com as informações expostas no Quadro 3 foi possível averiguar que a Cooperativa Omega possui entre os seus fornecedores, grandes empresas multinacionais reconhecidas internacionalmente pela excelência e qualidade na fabricação dos produtos que dedicam-se a comercializar.

Visto de forma estratégica, esta parceria fortalece a Cooperativa perante o mercado no momento em que estes fornecedores preocupam-se constantemente em entregar novas tecnologias aos produtores rurais vislumbrando uma maior produtividade por área cultivada. $\mathrm{O}$ fato mencionado comprova-se mediante inúmeras palestras e cursos que são fornecidos pelas multinacionais aos funcionários da Omega e, inclusive, aos produtores rurais associados em diversos encontros promovidos em parceria com os fornecedores citados.

\subsubsection{Clientes}

Os clientes associados à Omega Cooperativa compreendem desde pequenos a grandes produtores. Os mesmos estão localizados em 15 municípios da região central e meio oeste do Rio Grande do sul, que são: Santa Maria, Restinga seca, São Sepé,
Cachoeira do Sul, Rosário do Sul, São Gabriel, Manoel Viana, São Francisco de Assis, Cacequi, São Vicente do Sul, São Pedro do Sul, Jaguari, Mata, Itaara e Formigueiro.

A época das compras por parte dos clientes, em sua maioria ocorre entre os meses de setembro, outubro e novembro, podendo se estender até o mês de março. No restante do ano, o volume das compras é significativamente inferior, devido ao fato do período de entressafra. Quando as compras são efetuadas de maneira antecipada, antes do período da cultura, os produtos ficam armazenados na Omega e o produtor rural os retira de acordo com a sua necessidade, mesmo já tendo sido efetuado o pagamento. Este pode ser feito à vista, com recursos próprios do produtor ou financiamento bancário, ou também pagamento após a colheita mediante aprovação do cadastro do produtor.

Os clientes mais antigos, que são internamente classificados com um maior grau de confiabilidade tem a possibilidade de realizar compras por telefone direto com o vendedor. Casos como estes ocorrem quando o cliente, produtor rural, encontra-se em sua propriedade e identifica a necessidade de aplicação de determinado produto podendo, portanto, ligar 
para um vendedor, efetuar a compra e solicitar a entrega imediatamente, sujeito apenas à disponibilidade de transporte por parte da empresa.

Por fim, identificou-se que os clientes, em sua maioria, estão na atividade agrícola há mais de 10 anos e também, que boa parte destes são parceiros da Cooperativa Omega desde o início das atividades da mesma. A seguir, será apresentada a análise microambiental no que tange a concorrência.

\subsubsection{Concorrentes}

Mediante a realização deste estudo, identificouse na data de realização do mesmo, que os principais concorrentes diretos e indiretos da Omega, na região de Santa Maria são: Camera Agroalimentos S.A, Camsul e A Granja. O Quadro 4 adiante trará uma síntese das informações a respeito destas empresas identificadas como concorrentes da Cooperativa.

Quadro 4 - Concorrentes da Cooperativa

\begin{tabular}{|c|c|}
\hline Empresa & Descrição \\
\hline Camera Agroalimentos S.A. & $\begin{array}{l}\text { Permanece o ano inteiro em contato com o produtor rural, } \\
\text { acompanhando o plantio, a colheita e a comercialização de } \\
\text { suas diversas culturas. Esta foi fundada em } 1971 \text { na cidade } \\
\text { de Tucunduva, próximo a Santa Rosa, e atua na região de } \\
\text { Santa Maria desde } 2010 \text {. }\end{array}$ \\
\hline CAMSUL & $\begin{array}{l}\text { A CAMSUL, Cooperativa Agrícola Mista Sul Riograndense } \\
\text { LTDA, foi fundada no dia cinco de abril de 2002, em Santa } \\
\text { Maria, estado do Rio Grande do Sul, Brasil, nas dependên- } \\
\text { cias do prédio na Av. João Machado Soares, 3471, atuando } \\
\text { no ramo agropecuário. }\end{array}$ \\
\hline A Granja Com. E Representações & $\begin{array}{l}\text { Foi fundada em } 2005 \text { na cidade de Santa Maria e está sedia- } \\
\text { da no Km } 3 \text { da RS 509. Fornece uma linha completa de } \\
\text { defensivos agrícolas para as culturas de soja e arroz. }\end{array}$ \\
\hline
\end{tabular}

Fonte: Elaborado pelos autores

A Cooperativa Omega buscando minimizar os possíveis impactos que a concorrência possa lhe oferecer procura desenvolver e oferecer um amplo portfólio de produtos e serviços aos seus clientes. Dentre estes, pode-se salientar: o investimento em assistência técnica eficiente, participação no desenvolvimento de novas tecnologias de aplicação e novos nichos de mercado para produtos formulados, fornecimento de insumos agrícolas de qualidade e a preços compensadores, realização do recebimento, beneficiamento, armazenamento e comercialização da produção agrícola além de produzir e comercializar as suas próprias sementes.

Ainda, procurando sobressair-se à concorrência, a Cooperativa Omega apresenta alguns diferenciais que poderão ser visualizados a seguir.

- Fornecimento de assistência técnica diretamente na propriedade rural, oferecendo serviços que vão desde a regulagem de máquinas e equipamentos até a escolha dos melhores produtos e do momento oportuno da aplicação;
- Busca constante por fornecedores de insumos que empreguem tecnologia de última geração no desenvolvimento dos seus produtos;

- Busca pela satisfação plena do associado por meio de uma relação de confiança mútua com a cooperativa e o cliente.

\subsubsection{4 Órgãos Reguladores}

O principal órgão regulador é a OCERGS que é Sindicato e Organização das Cooperativas do estado do Rio Grande do Sul, que é a entidade responsável pela criação das normas de funcionamento das cooperativas.

No que diz respeito à regulação ambiental, os órgãos ambientais responsáveis são: Fundação Estadual de Proteção Ambiental (FEPAM), Instituto Brasileiro do Meio Ambiente e dos Recursos Naturais Renováveis (IBAMA) e a secretaria de agricultura do estado e o ministério da agricultura federal.

\section{Considerações Finais}


Os últimos acontecimentos de ordem econômica, política e social têm exercido maiores cobranças das organizações no sentido de otimização dos processos de gestão. Em virtude disto, a aplicação de uma profunda análise do ambiente de marketing possui uma relevância ainda maior nas rotinas administrativas das organizações.

No caso das cooperativas, o grau de importância não diminui, muito pelo contrário. Observando este cenário, buscou-se aplicar a análise em uma das mais importantes cooperativas agrícolas situadas na cidade de Santa Maria - RS buscando interpretar as variáveis ambientais inerentes à Cooperativa Omega.

Portanto, o presente trabalho contou com o objetivo central de realizar a análise ambiental de marketing da Omega, Cooperativa de agricultores parceiros da região centro-oeste do Rio Grande do Sul. Desta forma, procurou-se por meio de uma pesquisa de campo investigar o ambiente a nível micro e macro da cooperativa em questão.

A análise ambiental de marketing efetuada, contou com a avaliação criteriosa das variáveis contidas no macro e microambiente da Cooperativa. A nível macroambiental analisaram-se o ambiente econômico, político legal, sociocultural, tecnológico e natural da Cooperativa Omega.

Já a nível microambiental, a análise pautou-se na investigação dos fornecedores, clientes, concorrentes e órgãos reguladores que pertencem ao ambiente da Cooperativa. A partir do minucioso estudo da análise ambiental de marketing concretizada, entende-se que a Cooperativa poderá traçar, em conjunto com os seus dirigentes, diversas estratégias de incremento na competitividade e no aumento da lucratividade da Omega.

\section{Referências}

ALMEIDA, J. R.; MELLO, C. S. dos.; CALVALCANTI, Y. Gestão ambiental: planejamento, avaliação, implantação, operação e verificação. Rio de Janeiro: Thex, 2001.

BAYER. Bayer CropScience. Disponível em: < http://www.bayercropscience.com.br/site/aempre sa/quemsomos.fss> Acesso em: 05 Nov. 2015.
BOONE, L. E.; KURTZ, D. L. Marketing contemporâneo. Rio de Janeiro: LTC Editora, 1998.

BUFFON S.A. Buffon Fabricante de Fertilizantes. Disponível em: < https://complexbuffon.wordpress.com/> Acesso em: 05 nov. 2015.

BUNGE. A Bunge: Perfil. Disponível em: < http://www.bunge.com.br/Bunge/>. Acesso em: 05 nov. 2015.

CHEMTURA. Chemtura: a química é o nosso futuro. Disponível em: < http://pt.chemtura.com/corporatev2/v/index.jsp? vgnextoid=6a6238f $220 \mathrm{~d} 6 \mathrm{~d} 210 \mathrm{VgnVCM} 10000007538$ 10aRCRD\&vgnextchannel=6a6238f $220 \mathrm{~d} 6 \mathrm{~d} 210$ Vgn-

VCM1000000753810aRCRD\&vgnextfmt=defau lt>. Acesso em: 05 nov. 2015.

CHIAVENATO, I. Planejamento Estratégico: Fundamentos e Aplicações. São Paulo: Campus, 2004.

CHIAVENATO, I. Administração: teoria, processo e prática. Rio de Janeiro: Elsevier, 2007.

FMC. Fmc Corporation. Disponível em: < https://www.fmcagricola.com.br/index.aspx $>$. Acesso em: 05 nov. 2015.

GIL, Antônio Carlos. Como elaborar projetos de pesquisa. São Paulo: Atlas, 1991.

IHARA. Ihara ontem. Disponível em: < http://www.ihara.com.br/institucional>. Acesso em: 05 nov. 2015.

KOTLER, P.; ARMSTRONG, G. Introdução ao Marketing. 4 ed. Rio de Janeiro: LTC, 2000.

KOTLER, P.; KELLER, K. Administração de marketing. 12 ed. São Paulo: Pearson Prentice Hall, 2006.

MINADEO, R. Gestão de Marketing. São Paulo: Atlas, 2008. 
MONSANTO. Monsanto o que faz. Disponível em: $<\quad$ http://www.monsanto.com/global/br/quemsomos/pages/default.aspx>. Acesso em: 08 nov. 2015.

NORTOX. Conheça a Nortox. Disponível em: < http://www.nortox.com.br/institucional/conhecaa-nortox>. Acesso em: 05 nov. 2015.

NUNES, P. Ciências econômicas e empresariais. $2009 . \quad$ Disponível em: <http://www.knoow.net/cienceconempr/gestao>. Acesso em: 07 dez. 2012.

PALMER, A. Introdução ao Marketing: teoria e prática. São Paulo: Ática, 2006.

PAULA, J. C. N. Avaliação do desempenho sociocultural das empresas. Disponível em: $<$ http://www.webartigos.com/artigos/avaliacaodo-desempenho-sociocultural-dasempresas/62210/\#ixzz26IIODqXD>. Acesso em: 11 set. 2012.

RIBEIRO, A.; PICININ, C. T. Avaliação do microambiente de marketing como forças e fraquezas do setor supermercadista: um estudo de caso. Revista Brasileira de Administração Científica, Aquidabã, v. 3, n. 3, Jul./Dez., 2012.

SEBRAE, Saiba como escolher seus fornecedores. Disponível em: http://www.sebrae.com.br/customizado/acesso-amercados/conheca-seu-mercado/fornecedores. Acesso em: 10 set. 2012. 